\title{
Validation of the Spanish version of the Amsterdam Preoperative Anxiety and Information Scale (APAIS)
}

\author{
Manuel Vergara-Romero ${ }^{1,3^{*}}$, José Miguel Morales-Asencio ${ }^{2}$, Angelines Morales-Fernández ${ }^{1}$, \\ Jose Carlos Canca-Sanchez ${ }^{1}$, Francisco Rivas-Ruiz ${ }^{1}$ and Jose Antonio Reinaldo-Lapuerta ${ }^{1}$
}

\begin{abstract}
Background: Preoperative anxiety is a frequent and challenging problem with deleterious effects on the development of surgical procedures and postoperative outcomes. To prevent and treat preoperative anxiety effectively, the level of anxiety of patients needs to be assessed through valid and reliable measuring instruments. One such measurement tool is the Amsterdam Preoperative Anxiety and Information Scale (APAIS), of which a Spanish version has not been validated yet.

Objective: To perform a Spanish cultural adaptation and empirical validation of the APAIS for assessing preoperative anxiety in the Spanish population.

Methods: A two-step forward/back translation of the APAIS scale was performed to ensure a reliable Spanish cultural adaptation. The final Spanish version of the APAIS questionnaire was administered to 529 patients between the ages of 18 to 70 undergoing elective surgery at hospitals of the Agencia Sanitaria Costa del Sol (Spain). Cronbach's alpha, homogeneity index, intra-class correlation coefficient, and confirmatory factor analysis were calculated to assess internal consistency and criteria and construct validity.

Results: Confirmatory factor analysis showed that a one-factor model was better fitted than a two-factor model, with good fitting patterns (root mean square error of approximation: 0.05, normed-fit index: 0.99, goodness-of-fit statistic: 0.99). The questionnaire showed high internal consistency (Cronbach's alpha: 0.84$)$ and a good correlation with the Goldberg Anxiety Scale (CCl: 0.62 (95\% Cl: 0.55 to 0.68).
\end{abstract}

Conclusions: The Spanish version of the APAIS is a valid and reliable preoperative anxiety measurement tool and shows psychometric properties similar to those obtained by similar previous studies.

Keywords: Preoperative anxiety, Questionnaires, Validation studies

\section{Background}

Patients undergoing elective surgery often feel anxiety due to the risks involved and the unfamiliarity of the situation. It is estimated that $11 \%$ to $92 \%$ of patients undergoing surgery experience anxiety $[1,2]$.

The level of preoperative anxiety felt by each patient varies and is dependent on multiple factors [3]. These include the prognosis of the intervention, fears about the anesthetic and postoperative pain, and concerns

\footnotetext{
* Correspondence: mvergara@hcs.es

${ }^{1}$ Agencia sanitaria costa del sol, Málaga, Marbella, Spain

${ }^{3}$ Hospital Costa del Sol, Autovia A-7 KM, 18729603 Málaga, Spain

Full list of author information is available at the end of the article
}

about the outcome of the procedure $[4,5]$. However, a range of factors related to the sociodemographic and psychosocial characteristics of the patient also need to be considered, for example, personal anxiety levels, personality traits, sensitivity to pain, and the use of coping strategies. Additionally, other important variables include preexisting diseases, the complexity of the intervention, previous surgical experiences, and prior information received [6].

Preoperative anxiety is associated with a negative emotional state and generates a physiological activation of the body to face a perceived risk. This may negatively affect the development of the surgical intervention [3]. It 
is amply demonstrated that anxiety levels increase before an intervention, triggering a stress response which includes the release of catecholamines, sympathetic hyperactivity, hyper-metabolism, neuroendocrine changes, electrolyte alterations and immunological modifications [7]. Patients with a high level of preoperative anxiety require higher doses of anesthetics and need more peri- and postoperative analgesia [4, 8]. This often results in a longer hospital stay, increases the risk of readmission after surgery and raises morbidity and mortality [9] rates.

These complications make evident that preoperative anxiety needs to be assessed and addressed, supporting the routine administration of preoperative anxiolytics to all surgical patients [10]. Most scales for assessing anxiety (Goldberg Anxiety Scale, GADS [11]; State-Trait Anxiety Inventory, STAI [12]; Depression, Anxiety and Stress Test, DASS [13]; Hospital Anxiety and Depression, HADS [14]; Visual Analogue Scale for Anxiety, VAS-A [15]) have not been validated for surgical patients and do not evaluate their information needs, as they have not been specifically developed to measure preoperative anxiety. Extensive evidence has shown that preoperative information plays a vital role in reducing preoperative anxiety [16]. Interventions such as nursing preoperative visits or psychoeducational and audiovisual interventions that provide patients with additional information on the procedure to take place have shown reduction of anxiety [17-19].

In 1996, Moermann et al. developed the Amsterdam Preoperative Anxiety and Information Scale (APAIS) [20], a self-reported questionnaire specifically validated for assessing preoperative anxiety. APAIS is a useful, easy-to-use, clinically relevant instrument with good acceptance among patients and a simple format that facilitates analysis. This scale has been validated and translated into several languages [21], namely Dutch [20] English [22] German [6] French [23], Japanese [24] Slovak [25], Malay [21], and Indonesian [26]. Although APAIS has been previously used in Spanish studies [27-30], a validated Spanish version did not exist prior to our study.

\section{Methods}

\section{Aim}

The aim of this study was to carry out a Spanish cultural adaptation of the and empirical psychometric validation of the APAIS for the Spanish population.

\section{Design}

A psychometric validation study was conducted for adaptation of the APAIS scale.

\section{Setting}

The study was carried out at hospitals under the management of the Agencia Sanitaria Costa del Sol (Spain), a public institution with 350 beds that provide health care to 396.000 habitants. Patients were consecutively recruited between July 2015 and March 2016.

\section{Study subjects}

The sample included patients with ages ranging from 18 to 70 undergoing elective surgery in the specialties of general surgery, urology, gynecology, orthopedics, otolaryngology, ophthalmology and dermatology. The study subjects spoke and understood Spanish and voluntarily provided consent to participate in the study. Exclusion criteria were: psychiatric disease and/or cognitive impairment confirmed in clinical records, self-reported severe sensory disability preventing the subject from understanding or undergoing the tests (i.e. severe deafness), or who were not sufficiently proficient in Spanish.

The types of anesthesia administered included general, regional and local anesthesia in a hospitalization regimen of inpatient surgery and major and minor ambulatory surgery.

Some patients could have been administered an anxiolytic drug immediately before surgery, and were asked to complete the APAIS and GADS questionnaires prior to entering the operating room.

Sample size was calculated following the method of MacCallum et al. [31], namely: assuming a null hypothesis of a root mean square error of approximation between 0.04 and 0.08 with an alpha value of 0.05 and a statistical power of 0.8 and a maximum of 18 degrees of freedom, a sample size of 500 patients was obtained. This size was increased by $5 \%$ in anticipation of possible loss to follow-ups.

\section{Description of the measuring instrument and variables}

APAIS is a self-reported six-item questionnaire that has been validated for assessing preoperative anxiety. The scale is divided into two subscales exploring three aspects of preoperative anxiety: anesthesia, surgery (items 1,2, 4 and 5) and need for information (items 3 and 6). Each question is rated on a fivepoint Likert's scale, where a value of 1 indicates "not anxious at" all and 5 means "extremely anxious". The cut-off points for the overall score established by the authors of the original version are 11 and up to 13 , when used for research [20]. APAIS has also been reported to be useful as a predictor of early postoperative pain [32].

Patient sociodemographic variables, comorbidities, anesthetic risk (ASA) and history of previous surgery, amongst other data, were recorded. Anxiety was 
measured using the Spanish version of the Goldberg Depression and Anxiety scales (GADS) [33]. The scale had good psychometric properties (it has a onedimensional structure that explained $72 \%$ of variance, a Cronbach's alpha of 0.936 , and a cut-off point of $10 \mathrm{ob}-$ tained a sensitivity of $86.8 \%$, and specificity of $93.4 \%$ ), and confirmed that it could be reliably used by health professionals not specialized in mental health, such as anesthetists and surgical nurses.

\section{Data collection}

Surgical nurses previously trained in the implementation of the scales informed the patients about the procedure and obtained informed consent from patients who met inclusion criteria. Data were collected through face-toface interviews in the surgical area immediately prior to surgery.

\section{Ethical issues}

This study was approved by the Local Research Ethics Committee Costa del Sol (Spain), CEI (002-ma-PRAPAIS) on 26 March 2015, and was carried out in accordance with the ethical principles as set out in the Declaration of Helsinki. Written consent was obtained from all the participants in the study.

\section{Spanish cultural adaptation}

It was performed according to the methodology described by Guillemin et al. [34] and ISPOR guidelines [35]. Such method includes the following stages: i) translation of the source version into the target language; ii) use of qualitative methods to check cultural adaptation to the local population; and iii) back translation from the target language to the source language to verify that the underlying meaning of questions was appropriately transferred (Fig.1).

First of all, authorization was obtained from the authors of the original scale to carry out the Spanish cultural adaptation of their scale. Next, two native Spanish language translators prepared draft translations of the original scale separately. The translators reviewed their two translations with the research group and produced an adapted version of the scale. Following this, a blinded back translation was performed on the adapted version and compared with the original scale to resolve discordances. A second adapted version of the questionnaire was then produced. The understandability, clarity and familiarity of the Spanish version were evaluated through cognitive debriefing using inquiry and reformulation techniques (Table 1).

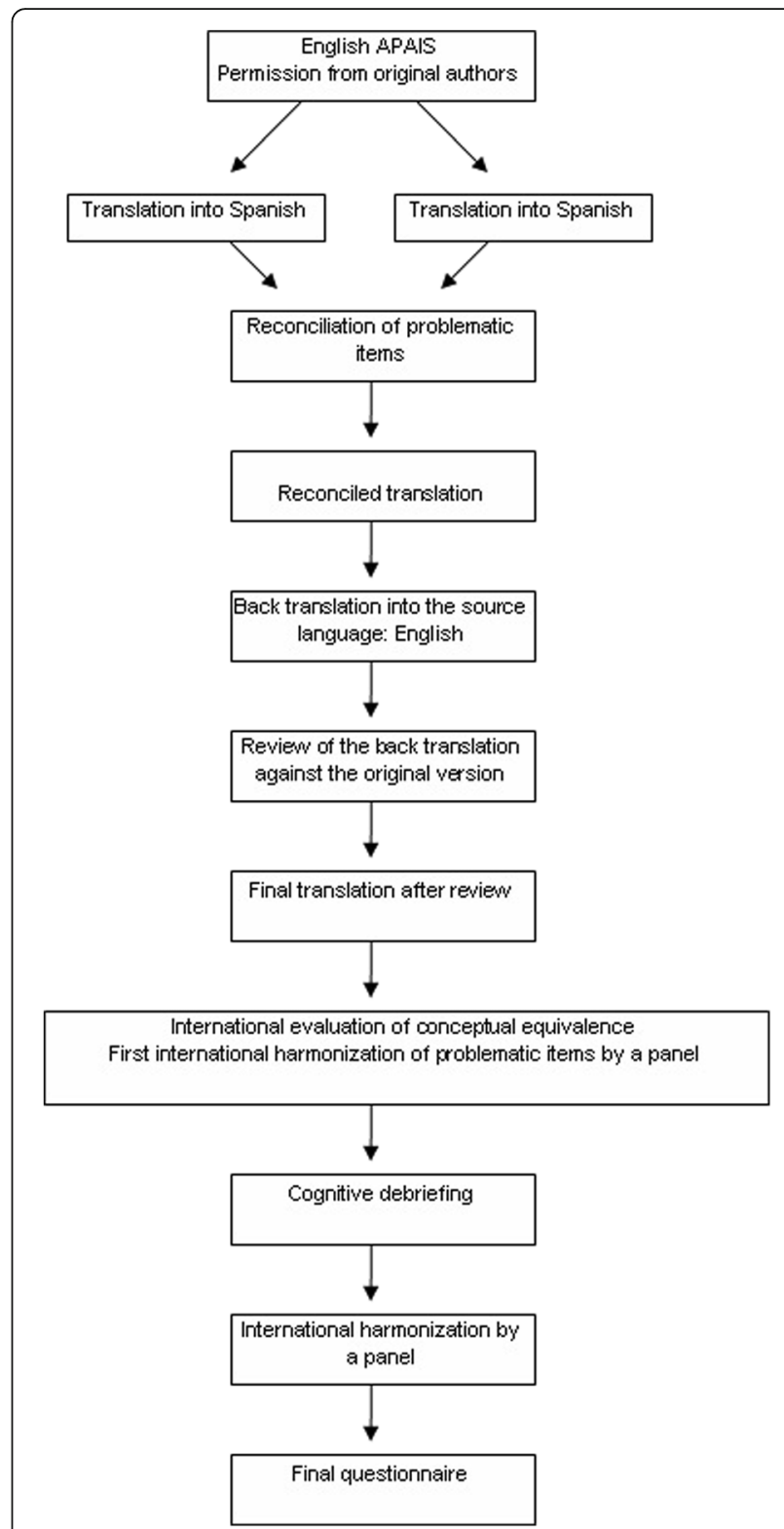

Fig. 1 Process of cross-cultural adaptation

\section{Statistical analysis}

Descriptive analysis was performed of the sociodemographic and clinical variables. The normality of the distribution of all variables was evaluated by the Kolmogorov-Smirnov test, and the skewness, kurtosis and histograms of the distributions were all ascertained. Bivariate analyses were carried out using the Student's t and the chi-square tests, in accordance with the characteristics of the variables analysed, when they were normally distributed. Otherwise, non-parametric tests such as the Wilcoxon test and the Mann-Whitney $\mathrm{U}$ test were used. One-way ANOVA was used to determine quantitative and qualitative relationships where appropriate, with measures of central robustness in cases of non- 
Table 1 Translated items of Amsterdam Preoperative Anxiety and Information Scale (APAIS)

\begin{tabular}{ll}
\hline Original items & Spain items \\
\hline 1. I am worried about the anaesthetic. & 1. Estoy preocupado por la anestesia \\
2. The anaesthetic is on my mind continually. & 2. Pienso en la anestesia continuamente \\
3. I would like to know as much as possible about the anaesthetic. & 3. Me gustaría saber lo máximo posible acerca de la anestesia \\
4. I am worried about the procedure. & 4. Estoy preocupado por la operación \\
5. The procedure is on my mind continually. & 5. Pienso en la operación continuamente \\
6. I would like to know as much as possible about the procedure & 6. Me gustaría saber lo máximo posible acerca de la operación
\end{tabular}

homoscedasticity (determined by Levene's test), using the Welch and Brown-Forsythe tests. If any of the assumptions necessary for the ANOVA test were not met, the Kruskall-Wallis test was performed.

Item-endorsement was determined by observing ceiling and floor effects. Internal consistency was assessed by Cronbach's alpha; inter-item correlation and homogeneity index were determined. Construct validity was assessed by exploratory factor analysis using both principal axis factoring with oblique rotation (Oblimin), and principal component extraction with Varimax rotation on a randomized sub-sample of 155 subjects. Sample adequacy and level of inter-item correlation were previously evaluated by the Kaiser-Meyer-Olkin test and Bartlett's sphericity test. Confirmatory factor analysis was subsequently performed both in the 374 resting subjects and in the whole sample, using the following indices of fit: CMIN/DF, root mean square error of approximation index (RMSEA) and its confidence interval $(90 \% \mathrm{CI})$, normed fit index (NFI), comparative fit index (CFI) and goodness of fit index (GFI). Multivariate normality was determined by Mardia's coefficient. Statistical analysis was performed using IBM SPSS version 22 and AMOS 21.

\section{Results}

\section{Content validity}

A panel of six experts (an anesthetist, two $\mathrm{PhD}$ nurses and three nurses with a master's degree) reviewed the initial two translations performed by the two native speakers to produce a final version that was back translated into the source language. The panel verified the conceptual equivalence of this version and decided to replace "intervención" with "operación" (Items 4, 5 and 6), a much more common term in Spanish. Next, 10 patients aged 45 to 65 years equally distributed by age and sex underwent individual semi-structured cognitive debriefing separately. The purpose of cognitive debriefing was to assess the interpretation of questions by respondents, explore if the terms employed were appropriate, and verify that the items were culturally applicable. All respondents described the items of the questionnaire as clear and understandable. Consequently, it was deemed that no items required modification due to misinterpretation or lack of understanding.

\section{Empirical validation}

Of the 549 subjects recruited, 20 were excluded for not meeting inclusion criteria, and 18 due to errors in




Table 2 Characteristics of the sample

\begin{tabular}{|c|c|c|c|c|}
\hline & Male $288(54.4 \%)$ & Female 241 (41.6\%) & Total $(n=529)$ & \\
\hline & Mean (SD) or $n(\%)$ & Mean (SD) or $n(\%)$ & Mean (SD) or n (\%) & $p$ \\
\hline Age & $50.31(13.87)$ & $50.95(15.326)$ & $50.60(14.54)$ & 0.902 \\
\hline Regular anxiolytic treatment & $54(18.8)$ & $14(5.8)$ & $68(12.9)$ & $<0.0001$ \\
\hline Education level & & & & 0.070 \\
\hline No education & $37(12.8)$ & $32(13.3)$ & $69(13.0)$ & \\
\hline Primary Education & 113(39.2) & $98(40.7)$ & $211(39.9)$ & \\
\hline Secondary Education & 110(38.2) & $72(29.9)$ & $182(34.4)$ & \\
\hline Higher Education & $28(9.7)$ & $39(16.2)$ & $67(12.7)$ & \\
\hline Specialty & & & & $<0.0001$ \\
\hline Surgery & $69(24)$ & $60(24.9)$ & $129(24.4)$ & \\
\hline Urology & 23(8) & $60(24.9)$ & $83(15.7)$ & \\
\hline Gynecology & $61(21.2)$ & - & $61(11.5)$ & \\
\hline Traumatology & $54(18.8)$ & $52(21.6)$ & $106(20.0)$ & \\
\hline ENT & $16(5.6)$ & $12(5)$ & $28(5.3)$ & \\
\hline Ophtalmology & $32(11.1)$ & $37(15.4)$ & $69(13)$ & \\
\hline Dermatology & $33(11.5)$ & $20(8.3)$ & $53(10.0)$ & \\
\hline Procedure & & & & 0.750 \\
\hline Surgery & 40(13.9) & $37(15.4)$ & $77(14.6)$ & \\
\hline Diagnostic surgery & $26(9.0)$ & $18(7.5)$ & $44(8.3)$ & \\
\hline Non-oncological surgery & $222(77.1)$ & 186(77.2) & $408(77.1)$ & \\
\hline Hospitalization regimen & & & & 0.174 \\
\hline Inpatients & 184(63.9) & 171(71.0) & $355(67.1)$ & \\
\hline Ambulatory Major Surgery & $55(19.1)$ & $41(17.0)$ & $96(18.1)$ & \\
\hline Outpatient & $49(17.0)$ & $29(12.0)$ & $78(14.7)$ & \\
\hline History of previous surgery & & & & 0.701 \\
\hline Yes & 215(74.9) & 177(73.4) & $392(74.2)$ & \\
\hline No & $72(25.1)$ & $64(26.6)$ & $136(25.8)$ & \\
\hline Have been informed on diagnosis & & & & 0.454 \\
\hline Yes & 279(96.9) & 236(97.9) & $515(97.4)$ & \\
\hline No & $9(3.1)$ & $5(2.1)$ & $14(2.6)$ & \\
\hline Have been informed on the procedure & & & & 0.393 \\
\hline Yes & 254(88.2) & 217(90.0) & $471(89.0)$ & \\
\hline No & $34(11.8)$ & $23(9.5)$ & $57(10.8)$ & \\
\hline Anesthetic risk & & & & 0.002 \\
\hline ASA I & 106(36.8) & 103(42.7) & 209(39.5) & \\
\hline ASA $\|$ & $161(55.9)$ & 101(41.9) & $262(49.5)$ & \\
\hline ASA III & $21(7.3)$ & $36(14.9)$ & $57(10.8)$ & \\
\hline ASA IV & - & $1(0.4)$ & $1(0.2)$ & \\
\hline Type of Anesthesia & & & & $<0.0001$ \\
\hline General & 113(39.2) & $66(27.4)$ & $179(33.8)$ & \\
\hline Loco-regional & $81(28.1)$ & $111(46.1)$ & $192(36.3)$ & \\
\hline Local & $94(32.6)$ & $64(26.6)$ & $158(29.9)$ & \\
\hline
\end{tabular}


Table 3 Inter-item correlation matrix

\begin{tabular}{|c|c|c|c|c|c|c|}
\hline Item & 1 & 2 & 3 & 4 & 5 & 6 \\
\hline 1. I am worried about the anesthetic & 1000 & & & & & \\
\hline 2. The anaesthetic is on my mind continually & 0.822 & 1.000 & & & & \\
\hline 3. I would like to know as much as possible about the anaesthetic & 0.451 & 0.434 & 1000 & & & \\
\hline 4. I am worried about the procedure & 0.513 & 0.461 & 0.325 & 1000 & & \\
\hline 5. The procedure is on my mind continually & 0.517 & 0.556 & 0.351 & 0.791 & 1.000 & \\
\hline 6. I would like to know as much as possible about the procedure & 0.270 & 0.260 & 0.580 & 0.527 & 0.511 & 1.000 \\
\hline
\end{tabular}

questionnaire completion (Fig. 2). The characteristics of the 529 study subjects are detailed in Table 2, being general surgery the highest proportion of patients $(n=129$; $24.4 \%$ ), with a mean age of 50.6 years (SD: 14.54), 288 (54.4\%) were men, of whom 54 (18.8\%) used anxiolytics regularly, versus $5.8 \%$ in women $(p<0.0001)$.

According to the scores obtained from GAD7, anxiety levels in our study subjects were generally low (mean: 1.79; SD: 2.63), being higher in men with regards to women (2.35; SD; 2.93 vs 1.12; SD: $2.02 ; p<0.001$ ). No significant differences were observed in anxiety levels between the group that received anxiolytics prior to the procedure and the group who did not receive any drug (1.53; SD: 2.45 vs 1.58 ; SD: $2.70 ; p=0.07$ ). The highest anxiety levels were observed in patients undergoing gynecological surgery (2.72; SD: $3.18 ; p<0.0001)$, receiving general anesthetics (2.17; SD: $2.78 ; p=0.001)$, or using anxiolytics regularly (mostly men) (2.96 SD: 3.11 vs 1.62 ; $\mathrm{SD}: 2.51 p=0.001$ ) [36, 37]. Conversely, no significant differences in anxiety levels were observed regarding age, education level or history of previous surgery. No differences were found either between anxiety level and anesthetic risk (ASA I; 2.05; SD: 2.88; ASA II: 1.67; SD: 2.46; ASA III: 1.39; SD: $2.41 ; p=0.121$ ).

\section{Characteristics of the items and internal consistency of the APAIS instrument}

No ceiling or floor effects were detected in any item. No cases of score bunching above $85 \%$ were detected. The mean score on the scale was 12.87 (SD: 6.08) (range of possible values: $5-30)$. All items showed item-to-total correlations $>0.20$ (mean: 0.49) (Table 3). Cronbach's alpha was 0.84 (Table 4).

\section{Construct validity}

Exploratory factor analysis (EFA) by oblique rotation (Oblimin) with 155 subjects, yielded a two-factor model that explained $75.78 \%$ of variance, whereas exploratory factor analysis of main axis with Varimax rotation produced a two-factor model that explained $74.8 \%$ (75\%) of variance. Confirmatory factor analysis (CFA) showed that the one-factor model was better fitted than the twofactor model based on EFA, with good fitting patterns (Fig. 3). Multinormality analysis confirmed the validity of parameters (Table 5).

\section{Criteria validity}

Criteria validity was tested by means of ICC and ROC area from APAIS scores and Goldberg Depression and Anxiety scale, obtaining an intra-class correlation coefficient (ICC) of 0.62 (95\% CI: 0.55 to 0.68). The area under the curve (Fig. 4) for anxiety, as assessed by the APAIS scale, was 0.85 (95\% CI: 0.81 to 0.88 ) with a cutoff point of 14 .

\section{Discussion}

The objective of this study was to carry out a Spanish cultural adaptation and validation of the Spanish version of the APAIS scale. The methods used were consistent with the guidelines established in the literature [34, 35]. An equivalent Spanish version in conceptual and semantic terms was produced. The validation process revealed the strong psychometric properties of the Spanish version concerning reliability and validity.

The internal validity of the scale was tested using exploratory factor analysis (EFA). Estimations were initially performed for a two-factor model, as in the original

Table 4 Item-total correlation

\begin{tabular}{llll}
\hline & $\begin{array}{l}\text { Corrected Item-to-total } \\
\text { correlation }\end{array}$ & $\begin{array}{l}\text { Squared multiple } \\
\text { correlation }\end{array}$ & $\begin{array}{l}\text { Cronbach's alpha if item } \\
\text { removed }\end{array}$ \\
\hline I am worried about the anaesthetic & 0.650 & 0.713 & 0.821 \\
The anesthetic is on my mind continually & 0.648 & 0.713 & 0.823 \\
I would like to know as much as possible about the anaesthetic & 0.550 & 0.455 & 0.840 \\
I am worried about the procedure & 0.693 & 0.674 & 0.812 \\
The procedure is on my mind continually & 0.723 & 0.687 & 0.806 \\
I would like to know as much as possible about the procedure & 0.558 & 0.507 & 0.841 \\
\hline
\end{tabular}




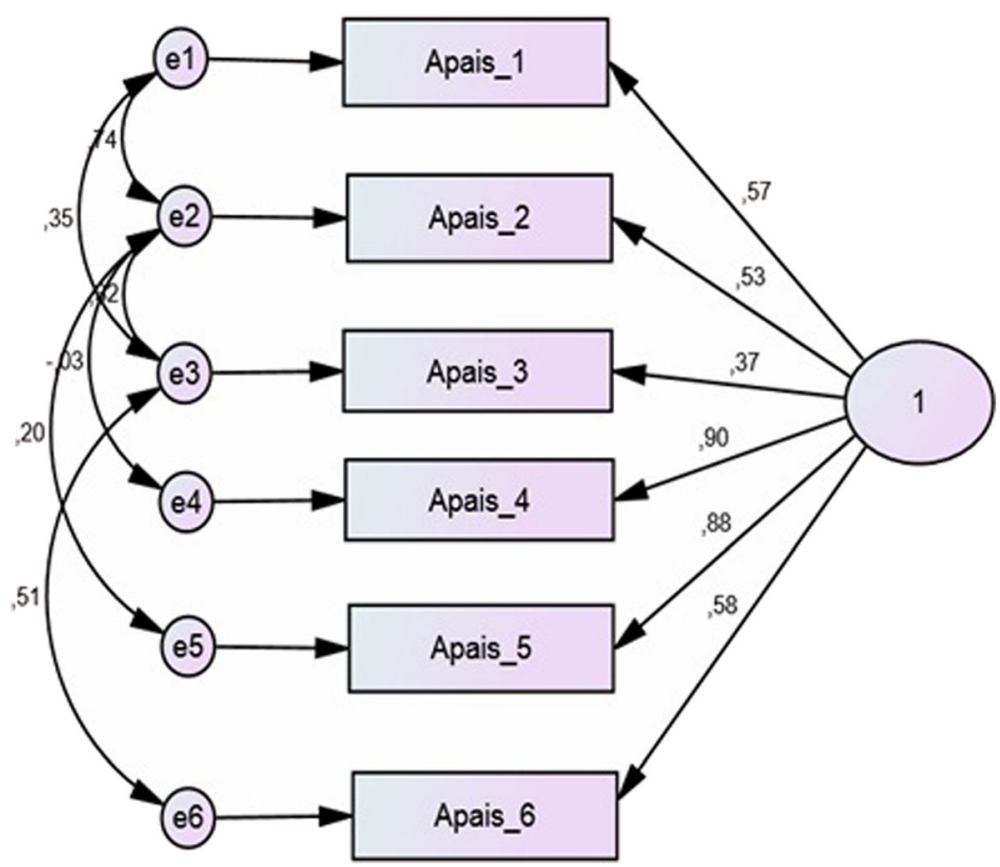

Fig. 3 Instrument structure

version. However, confirmatory factor analysis showed that the two-factor model from EFA did not fit the data well. This is frequent when robust factor analysis methods are used, since they usually show fits that are otherwise unacceptable with exploratory methods [38]. Therefore, a one-factor model was used.

The validity and reliability of the Spanish version is similar to that reported by the authors of the original instrument [20]. It is worth mentioning that anxiety and information needs were integrated into a single factor in the Spanish version, as they were considered different manifestations of the same latent variable. This modification may be related to cultural aspects, such as cultural beliefs about fear, or ways of coping to threats, or general knowledge about the surgical and anesthetic process, which evidences that the Spanish version of the scale required a cultural adaptation [39].

The anxiety levels detected in our study were low despite the fact that interviews were conducted immediately before surgery, which has been reported as the point of maximum anxiety in previous studies [7]. This could explain that in the criterion validity process, we found the best sensitivity and specificity values with a cut-off point slightly greater than the original authors [20].

Although no significant differences were observed between the group that received anxiolytics and the group which did not, the results obtained are consistent with those reported in previous studies. The patients undergoing gynecological surgery, receiving general anesthetics and using anxiolytics regularly (mostly men) were the subjects who showed the highest levels of anxiety. Interestingly, the relationship found between general anesthetics and anxiety was not observed in the French APAIS version [23], in which no correlation was found between the type of anesthetic and the levels of anxiety. On the other hand, the finding that men exhibited higher levels of anxiety might be explained by the fact that men took anxiolytic medication more frequently than women and previous studies have documented higher levels of preoperative anxiety in patients who regularly take psychopharmacological substances [37].

Table 5 Confirmatory factor analysis adjustment parameters

\begin{tabular}{llll}
\hline & Original & Two-factor model & One-factor model \\
\hline CMIN/DF & 28.29 & 22.49 & 2.40 \\
GFI & 0.88 & 0.92 & 0.99 \\
$\mathrm{NFI}$ & 0.87 & 0.92 & 0.99 \\
$\mathrm{CFI}$ & 0.88 & 0.93 & 0.99 \\
RMSEA $(90 \% \mathrm{Cl})$ & $0.48(0.46$ to 0.50$)$ & $0.202(0.17$ to 0.23$)$ & 0.05 (0.001 to 0.11$)$ \\
\hline
\end{tabular}




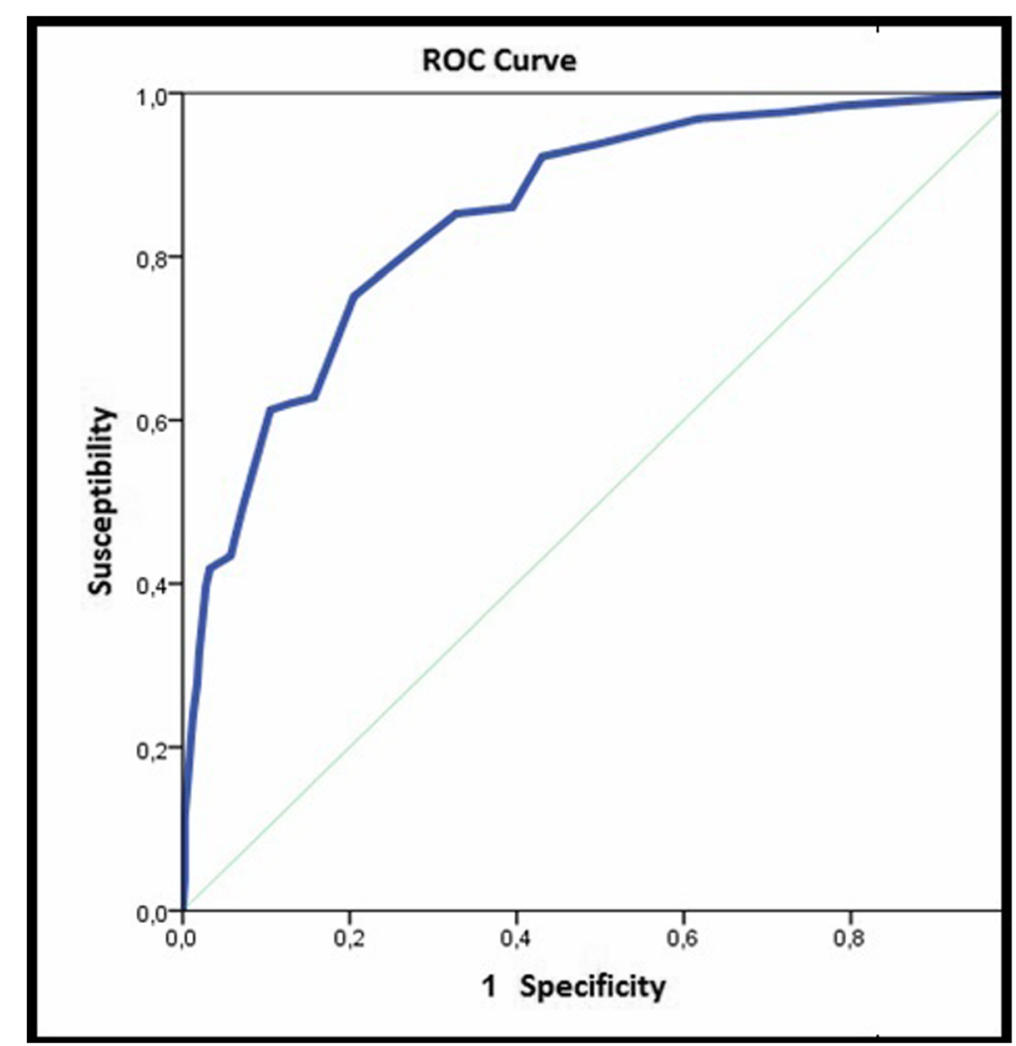

Fig. 4 Predictive validity using goldberg as gold standard

Differences by age, education level, or history of previous surgery were not significant, which is in agreement with the results obtained for the Japanese [24] and German [6] validation studies. These findings are consistent with those reported by other authors. It is important to point out that no differences were found between anxiety level and anesthetic risk. This means that perceived threat is independent from the risk factors that could be present prior to the surgery, so that interventions to prevent anxiety should not be guided by this criterion.

Unlike the original scale and subsequent versions in other languages, the validity of criteria of the Spanish APAIS scale was tested against GADS [11], with good results.

One limitation of this study was that the questionnaires were completed immediately prior to entering the operating room. It is possible that preoperative anxiety levels could variate depending on the moment of the evaluation (the imminence of the intervention could trigger the perception of threat and, thus, the anxiety level). Otherwise, the waiting time before the intervention has been reported as an important factor that influences preoperative anxiety [40], although this factor was not evaluated in our study.

\section{Conclusion}

This study confirms the validity and reliability of the Spanish version of the APAIS, showing it to be a useful, brief, clinically relevant instrument with high levels of acceptance among patients given in a format that facilitates analysis. The properties of this scale make its use possible as a standard measurement instrument for assessing preoperative anxiety, especially if validated versions are used.

\section{Abbreviations}

APAIS: the Amsterdam Preoperative Anxiety and Information Scale; CFI: Comparative fit index; Cl: Confidence interval; CMIN/DF: Root mean square error of approximation index (RMSEA) divided by degrees of freedom.; DASS: Depression, anxiety and stress test; EFA: Exploratory factor analysis; GADS: Goldberg anxiety scale; GFI: Goodness of fit index (GFI).; HADS: Hospital anxiety and depression; ICC: Intraclass correlation coefficient; NFI: Normed fit index; RMSEA: Root mean square error of approximation index; STAI: State-Trait anxiety inventory; VAS-A: Visual analogue scale for anxiety

\section{Acknowledgements}

We thank to the Hospital Costa del Sol for his help in the manuscript language review of this work and publication and we would give thanks to the surgical and anesthesia nurses who collaborated in the data collection.

\section{Funding}

This study was partially supported by the Health Care Agency Costa del Sol which provided funds for the dissemination of results. 


\section{Availability of data and materials}

The datasets used and/or analysed during the current study available from the corresponding author on reasonable request.

\section{Authors' contributions}

MVR participated in the conception and design of the study, conducted the data collection, analyze the data, and drafted the first version of the manuscript and reviewed the successive versions. JMMA participated in the conception and design of the study, analyzed the data, and reviewed the successive versions of the manuscript. AMF participated in the conception and design of the study, conducted the data collection, analyze the data, and drafted the first version of the manuscript and reviewed the successive versions. JCCS participated in the data collection, and reviewed the successive versions of the manuscript. FRR contributed to the analysis of data, and reviewed the successive versions of the manuscript. JRL participated in the data collection, and drafted the first version of the manuscript and reviewed the successive versions. All authors read and approved the final manuscript.

\section{Competing interests}

The authors declare that they have no competing interests in this section.

\section{Consent for publication}

Not applicable in this section.

\section{Ethics approval and consent to participate}

This study was approved by the Local Research Ethics Committee Costa del Sol (Spain) CEI (002-ma-PR-APAIS) on 26 March 2015, and was carried out in accordance with the ethical principles as set out in the Declaration of Helsinki. Written consent was obtained from all the participants in the study.

\section{Publisher's Note}

Springer Nature remains neutral with regard to jurisdictional claims in published maps and institutional affiliations.

\section{Author details}

${ }^{1}$ Agencia sanitaria costa del sol, Málaga, Marbella, Spain. ${ }^{2}$ Faculty of Health Sciences. Universlty of Málaga, Málaga, Spain. ${ }^{3}$ Hospital Costa del Sol, Autovia A-7 KM, 18729603 Málaga, Spain.

\section{Received: 4 November 2016 Accepted: 24 May 2017} Published online: 07 June 2017

\section{References}

1. Yilmaz M, Sezer $H$, Gürler $H$, Bekar M. Predictors of preoperative anxiety in surgical inpatients: preoperative anxiety. J Clin Nurs. 2012;21:956-64.

2. Wilson CJ, Mitchelson AJ, Tzeng TH, El-Othmani MM, Saleh J, Vasdev S, et al. Caring for the surgically anxious patient: a review of the interventions and a guide to optimizing surgical outcomes. Am J Surg. 2016;212:151-9.

3. de la Ansiedad T. Art Í Culoespecial. Rev Clín Med Fam. 2011;4:228-33.

4. Ali A, Altun D, Oguz BH, Ilhan M, Demircan F, Koltka K. The effect of preoperative anxiety on postoperative analgesia and anesthesia recovery in patients undergoing laparascopic cholecystectomy. J Anesth. 2014;28:222-7.

5. Theunissen M, Peters ML, Bruce J, Gramke H-F, Marcus MA. Preoperative anxiety and catastrophizing: a systematic review and meta-analysis of the association with chronic postsurgical pain. Clin J Pain. 2012;28:819-41.

6. Carus KP-UCG, Carus FB-UCG: The Amsterdam Preoperative Anxiety and Information Scale (APAIS)-the first trial of a German version Die Amsterdam Preoperative Anxiety and Information Scale (APAIS)-erste Erprobung einer deutschsprachigen Version..

7. Carrillo PM, Pla AC: Detección y actuación en la ansiedad preoperatoria inmediata. CIR MAY AMB. 2015:20(2):74-78.

8. Robleda G, Sillero-Sillero A, Puig T, Gich I, Baños J-E. Influence of preoperative emotional state on postoperative pain following orthopedic and trauma surgery. Rev lat am Enfermagem. 2014;22:785-91.

9. Navarro-García MA, Marín-Fernández B, de Carlos-Alegre V, Martínez-Oroz A, Martorell-Gurucharri A, Ordoñez-Ortigosa E, et al. others: Trastornos del ánimo preoperatorios en cirugía cardiaca: factores de riesgo y morbilidad postoperatoria en la unidad de cuidados intensivos. Rev Esp Cardiol. 2011; 64:1005-10.
10. Mirakhur RK. Preanaesthetic medication: a survey of current usage. J R soc med. 1991:84:481-3.

11. Montón C, Pérez Echevarria MJ, Campos R, García Campayo J, Lobo A. Anxiety scales and Goldberg's depression: an efficient interview guide for the detection of psychologic distress. Atención primaria Soc Esp Med Fam Comunitaria. 1993;12(6):345-9.

12. Grös DF, Antony MM, Simms LJ, McCabe RE. Psychometric properties of the state-Trait inventory for cognitive and somatic anxiety (STICSA): comparison to the state-Trait anxiety inventory (STAI). Psychol Assess. 2007;19:369-81.

13. Crawford JR, Henry JD. The depression anxiety stress scales (DASS): normative data and latent structure in a large non-clinical sample. Br J Clin Psychol. 2003;42:111-31.

14. Zigmond AS, Snaith RP. The hospital anxiety and depression scale. Acta Psychiatr Scand. 1983;67:361-70.

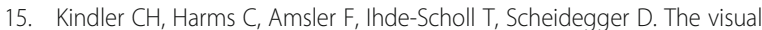
analog scale allows effective measurement of preoperative anxiety and detection of patients' anesthetic concerns. Anesth Analg. 2000;90:706-12.

16. Maurice-Szamburski A, Bruder N, Loundou A, Capdevila X, Auquier P. Development and Validation of a Perioperative Satisfaction Questionnaire in Regional Anesthesia. Anesthesiology. 2013;118:78-87.

17. Gómez-Urquiza JL, Hueso-Montoro C, Urquiza-Olmo J, Ibarrondo-Crespo R, González-Jiménez E, Schmidt-Riovalle J. A randomized controlled trial of the effect of a photographic display with and without music on pre-operative anxiety. J Adv Nurs. 2016;72:1666-76

18. Sadati L, Pazouki A, Mehdizadeh A, Shoar S, Tamannaie Z, Chaichian S. Effect of preoperative nursing visit on preoperative anxiety and postoperative complications in candidates for laparoscopic cholecystectomy: a randomized clinical trial. Scand J Caring Sci. 2013;27:994-8.

19. Ortiz J, Wang S, Elayda MA, Tolpin DA. Preoperative patient education: can we improve satisfaction and reduce anxiety? Braz J Anesthesiol Engl Ed. 2015;65:7-13.

20. Moerman $\mathrm{N}$, van Dam FS, Muller MJ, Oosting $\mathrm{H}$. The Amsterdam preoperative anxiety and information scale (APAIS). Anesth Analg. 1996;82:445-51.

21. Mohd Fahmi Z, Lai LL, Loh PS. Validation of the Malay version of the Amsterdam preoperative anxiety and information scale (APAIS). Med J Malaysia. 2015:70:243-8.

22. Boker A, Brownell $L$, Donen N. The Amsterdam preoperative anxiety and information scale provides a simple and reliable measure of preoperative anxiety. Can J Anesth. 2002;49:792-8.

23. Maurice-Szamburski A, Loundou A, Capdevila X, Bruder N, Auquier P. Validation of the French version of the Amsterdam preoperative anxiety and information scale (APAIS). Health Qual Life Outcomes. 2013;11:166.

24. Nishimori M, Moerman N, Fukuhara S, van Dam F, Muller MJ, Hanaoka K, et al. Translation and validation of the Amsterdam preoperative anxiety and information scale (APAIS) for use in Japan. Qual Life res. 2002;11:361-4.

25. Turzáková J: Anxiety and Coping in Hospitalized Patients. Measurement Tools and FindingsEdition: 1st, Publisher: Miedzynarodowa Fundacja "Scientia, Arts, Educatio", Krakow, Poland, Editors: Tomáš Sollár.2014.31-51

26. Perdana A, Firdaus MF, Kapuangan C. Khamelia -: Uji Validasi Konstruksi dan Reliabilitas Instrumen the Amsterdam preoperative anxiety and information scale (APAIS) Versi Indonesia. Maj Anest Dan Crit Care. 2016:33:279-86.

27. Hernández-Palazón J, Fuentes-García D, Falcón-Araña L, Rodríguez-Ribó A, García-Palenciano C, Roca-Calvo MJ. others: visual analogue scale for anxiety and Amsterdam preoperative anxiety scale provide a simple and reliable measurement of preoperative anxiety in patients undergoing cardiac surgery. Int Cardivascular Res J. 2015;9:1-6.

28. Doñate Marín M, Litago Cortés A, Monge Sanz Y, Martínez Serrano R. Aspectos de la información preoperatoria relacionada con la ansiedad del paciente programado para cirugía. Enferm Glob. 2015;14:170-80.

29. Ham Armenta KO, Pardo Morales RV: Nivel de ansiedad preoperatoria en las pacientes programadas a cirugía electiva en el Hospital de Ginecología y Obstetricia del IMIEM, mediante la escala de APAIS y escala de Spielberg. 2013.

30. Valenzuela-Millán J, Barrera-Serrano JR, Ornelas-Aguirre JM. Ansiedad preoperatoria en procedimientos Anestésicos. Cir Cir. 2010:78:151-6.

31. MacCallum R, Lee T, Browne MW. The issue of Isopower in power analysis for tests of structural equation models. Struct Equ Model Multidiscip J. 2010;17:23-41.

32. Kalkman JC, Visser K, Moen J, Bonsel JG, Grobbee ED, MKG M. Preoperative Prediction of Severe Postoperative Pain. Pain. 2003;105:415-23.

33. García-Campayo J, Zamorano E, Ruiz MA, et al. Cultural adaptation into Spanish of the generalized anxiety disorder-7 (GAD-7) scale as a screening tool. Health Qual Life Outcomes. 2010;8:8. 
34. Francis Guillemin CB. Guillemin F, Bombardier C, Beaton D. Cross-cultural adaptation of health-related quality of life measures: literature review and proposed guidelines. J Clin Epidemiol 12: 1417-32. J Clin Epidemiol. 1994;46: 1417-32.

35. Wild D, Grove A, Martin M, Eremenco S, McElroy S, Verjee-Lorenz A, et al. Principles of good practice for the translation and cultural adaptation process for patient-reported outcomes (PRO) measures: report of the ISPOR task force for translation and cultural adaptation. Value Health. 2005;8:94104.

36. Shevde K, Panagopoulos G. A survey of 800 patients' knowledge, attitudes, and concerns regarding anesthesia. Anesth Analg. 1991;73:190-8.

37. Caumo W, Schmidt AP, Schneider CN, Bergmann J, Iwamoto CW, Bandeira $\mathrm{D}$, et al. Risk factors for preoperative anxiety in adults. Acta Anaesthesiol Scand. 2001;45:298-307.

38. Piera PJF, Carrasco CA. El análisis factorial como técnica de investigación en psicología. Papeles Psicólogo. 2010;31:18-33.

39. van der Eijk C, Rose J. Risky business: factor analysis of survey data assessing the probability of incorrect Dimensionalisation. PLoS One. 2015;10: e0118900.

40. Aalouane R, Rammouz I, Tahiri-Alaoui D, Elrhazi K, Boujraf S. Determining factors of anxiety in patients at the preoperative stage. Neurosci Riyadh Saudi Arab. 2011:16:146-9.

Submit your next manuscript to BioMed Central and we will help you at every step:

- We accept pre-submission inquiries

- Our selector tool helps you to find the most relevant journal

- We provide round the clock customer support

- Convenient online submission

- Thorough peer review

- Inclusion in PubMed and all major indexing services

- Maximum visibility for your research

Submit your manuscript at www.biomedcentral.com/submit
Biomed Central 